\title{
El des-hacer de la violencia: socialización de una experiencia de atención psicosocial a niños y niñas víctimas de la violencia por conflicto armado en Colombia desde el marco interpretativo de las artes plásticas
}

Francisco Javier Portilla Guerrero ${ }^{1}$

\begin{abstract}
Resumen
El texto hace referencia a una experiencia de reflexión en un intento de inclusión social que busca hacer evidente cómo la violencia del conflicto Colombiano afecta el imaginario de los niños en los municipios de zona roja del departamento de Nariño. Busca explorar la forma en que el conflicto se hace evidente en las imágenes re-creadas por los niños en sus dibujos y cómo estos se convierten en un acto de comunicación y resistencia.
\end{abstract}

Palabras clave: violencia, desplazamiento, arte, desterritorialidad, territorialidad, hermeneutica, psicosocial

\footnotetext{
1 Maestro en Artes Plásticas, Tecnólogo en Cerámica, Licenciado en Educación Preescolar y Básica Primaria, Especialista en Estudios Latinoamericanos con énfasis en Educación e Investigación, Maestría en Etnoliteratura, diversos diplomados y capacitaciones en atención psicosocial, educación y arte; como artista 6 exposiciones individuales 25 colectivas, un Salón Regional y un Salón Nacional. Experiencia en proyectos de Atención Psicosocial y psicopedagógica con niños víctimas de desplazamiento y violencia por conflicto armado en Colombia para el ICBF regional Nariño, proyectos de investigación creación con comunidades víctimas del conflicto armado, para diferentes ONGH, Docente hora cátedra convocatoria en investigación creación del programa de maestría en artes visuales de la facultad de artes de la Universidad de Nariño, actualmente tutor de la Escuela de Ciencias de la Educación CEAD Pasto de la Universidad Nacional Abierta y a Distancia UNAD.
} 


\title{
El des-hacer de la violencia: socialización de una experiencia de atención psicosocial a niños y niñas víctimas de la violencia por conflicto armado en Colombia desde el marco interpretativo de las artes plásticas
}

\begin{abstract}
The text refers to an experience of reflection in an attempt to social inclusion which seeks to make evident the violence of the Colombian conflict affects the imagination of children in the red zone municipalities of Nariño department and how this is evident in the images re-created from his drawings as an act of communication and resistance.
\end{abstract}

Key Words: violence, displacement, art, deterritoriality, territoriality, hermeneutics, psychosocial.

Recibido: 07 de abril 2011 Aceptado: 28 de octubre 2011

Pero la muerte va también por el mundo vestida de escoba, lame el suelo buscando difuntos,

la muerte está en la escoba, es la lengua de la muerte buscando muertos, es la aguja de la muerte buscando hilo. Neruda

\section{Introducción}

El presente tejido es el resultado de una experiencia investigativa en curso que refleja la experiencia que el autor-en calidad de artista plástico e investigador social- desarrolló dentro del programa Unidad Móvil de Atención Psicosocial a Víctimas de la Violencia por Conflicto Armado en Colombia del ICBF, regional Nariño. Basándose en una interpretación desde el enfoque psicosocial de la población infantil víctima de la violencia en el departamento de Nariño 
durante el año 2003, se asume la plástica como elemento de proyecciones emocionales a través de los cuales se visibilizan los efectos de la violencia y desde allí los procesos de catarsis y resiliencia. El alcance de este acercamiento permitió desarrollar estrategias de intervención tendientes al desarrollo de la atención psicosocial en niños y niñas víctimas del conflicto, en aras de facilitar su recuperación emocional. Todas las expresiones pictóricas, textuales y orales registradas en el presente documento hacen parte de las experiencias directas de quienes convivieron y aún conviven con el conflicto.

La intención de este texto es dejar abierta la puerta a una reflexión que permita sentir responsabilidad directa frente a las invisibilidades de unas violencias de cuyas consecuencias somos culpables, si no por acción, al menos por omisión.

\section{Instrumentos metodológicos:}

La investigación tiene un enfoque histórico hermenéutico y sigue un método etnográfico que desde la observación, intenta comprender y dar sentido a hechos sociales que ocurren dentro de un marco circunstancial histórico y cultural. Tiene como instrumentos de recolección de información la recuperación de la historia colectiva, los talleres, los diálogos informales y los imagos. Específicamente, toma como base de interpretación hermenéutica los imagos de niños víctimas de la violencia de los municipios de La Cruz, Mosquera, Cumbitara y Leiva en el departamento de Nariño.

\section{Contextualización}

Colombia es un país donde muchas de sus praxis se derivan de violencias cuyos conflictos son responsables de las génesis imaginarias de sus ciudadanos. El presente tejido es una reflexión sobre los efectos del desplazamiento y el pesimismo latente que se construye cuando las ayudas para mejorar las adversas condiciones del ser humano víctima de la violencia y el desplazamiento por conflicto armado en Colombia son mínimas; pues sin duda, esta es una problemática de inmensas magnitudes que mantiene un aumento constante y que, hasta el momento, no presenta ninguna posibilidad eficaz y directa de solución. Igualmente, se pretende explorar cómo estas problemáticas pueden evidenciarse desde las expresiones plásticas realizadas por niños y niñas que viven a diario y de forma directa el conflicto armado.

El artículo primero de la ley 387 DE 1997 (julio 18) define como «desplazado» a toda persona que se ha visto forzada a migrar dentro del territorio nacional, abandonando su localidad de residencia o actividades económicas habituales porque su vida, su integridad física, su seguridad o libertad personales han sido vulneradas o se encuentran directamente amenazadas, con ocasión de cualquiera de las siguientes situaciones: conflicto armado interno, disturbios y tensiones interiores, violencia generalizada, violaciones masivas de los 


\section{Francisco Javier Portilla Guerrero}

El des-hacer de la violencia: socialización de una experiencia de atención psicosocial a niños y niñas víctimas de la violencia por conflicto armado en Colombia desde el marco interpretativo de las artes plásticas, artículo producto de la investigación

Derechos Humanos, infracciones al Derecho Internacional Humanitario $\mathrm{u}$ otras circunstancias emanadas de las situaciones anteriores que puedan alterar o alteren drásticamente el orden público. Parágrafo. El Gobierno Nacional reglamentará lo que se entiende por condición de desplazado.

Claudia una niña víctima de la violencia y el desplazamiento por conflicto armado tiene apenas doce años y escribe su historia como si se tratase de un cuento, uno de esos cuentos tristes que buscan en sus epílogos el tan anhelado final feliz:

Mi nombre es Claudia había una vez unos señores en una finca y después se fueron al pueblo y se estuvieron ahí, después se fue el papá y la mamá a otra ciudad entonces la madre se quedó con los tres hijos y como se queda sola una señora la invitó a dormir a la casa y estaba reblujada (refugiada) y habían escrito unas letras en la pared y la señora le pregunto a las hijas más grandes para quien será, para nosotros o para los dueños de la casa y en la pared decía les damos 24 horas para que desocupen el territorio pero no se fueron por que no sabían para quien era, después llamaron al señor o sea al papá y a los días llego el papá y le contó al esposo la esposa a la otra noche el padre estaba curando a un niño del cuajo y llegaron los guerrilleros y la señora que estaba con él se asustó y salió corriendo y los la señora y el señor con los hijos se quedaron y los guerrilleros los hicieron poner boca abajo y llamaron a la mama y le preguntaron el nombre la edad y ellos eran encapuchados y después llamaron al papá y le preguntaron lo mismo y después los hicieron parar y les dijeron les damos 24 horas para que salgan de aquí y si al otro día están aquí los matamos después se tuvieron que ir a otra ciudad y después se fueron a una finca y a todos los desplazados les dieron casas terrenos viven felices y les dan gracias a dios por que les han ayudado.

En un país que se define dentro de lenguajes de guerra, ser campesino al parecer es considerado, para quienes sustentan sus «ideas» en las armas, como un pecado capital que condena a seres humanos, niños, adultos y ancianos a renunciar a sus costumbres y a adaptarse a contextos nuevos, ajenos y en la mayoría de los casos, hostiles, que no proveen de los recursos necesarios para solventar una vida digna.

Cada día son más las familias que por efectos de la violencia se ven obligadas a renunciar a sus contextos sociales, económicos y culturales en pro de preservar su vida. Es el paso de la vida a la sub-vida, ya que una vez despojados de sus contextos las familias se ven enfrentadas a una serie de dramáticas circunstancias de mendicidad en relación a los pequeños auxilios del Estado u ONGs encargadas de aminorar los impactos absurdos del desplazamiento.

El desplazamiento constituye un problema de grandes implicaciones sociales que produce daños severos en la vida familiar y en cada uno de los miembros. 
Desarticula el tejido social, familiar y comunitario y afecta la salud mental, el proyecto de vida, la inseguridad emocional, la asunción de nuevos roles, la elaboración de duelos, el ajuste a nuevas situaciones generadas de conflictos y las dimensiones del tejido social en relación al nuevo entorno. Y trae consigo además, el desarraigo, la ausencia de sentido de pertenencia, desempleo, las condiciones infrahumanas de vivienda, entre otras. Estos son sólo algunos de los efectos derivados de la infamia que también afecta a las comunidades receptoras, quienes de un momento a otro sienten invadidos sus espacios y sus posibilidades de vivencia económica, social y cultural.

Si los derechos humanos se basan en el reconocimiento de la dignidad y el valor de la persona humana, estos adquieren sentido sólo desde su práctica, garantizando el desarrollo de la individualidad.

\section{En Nariño...}

De los treinta y cuatro artículos de la Ley 387, muy poco es lo que se logra hacer de manera directa para mejorar las condiciones de vida de las personas en condición de desplazamiento, ya que va en vía contraria de las dimensiones del desplazamiento: mientras la población desplazada aumenta, los recursos para la ayuda humanitaria disminuyen en razón del aumento del pie de fuerza, para una guerra que no da las mínimas muestras de al menos una posibilidad de resolución.

Las siguientes son algunas reflexiones derivadas de un conversatorio en el marco de la atención psicosocial realizada en el año 2002 a una serie de familias desplazadas re-ubicadas en el municipio de Pasto. El núcleo familiar en su conformación oscila por lo general entre tres hasta once miembros por promedio entre los que se destacan las madres cabeza de familia, uniones libres, hijos entre los cero y catorce años, sobrinos, adultos mayores, y muy frecuentemente uno de los miembros de la familia sufre de alguna discapacidad. Miembros de estas familias afirmaban: «[n]osotros fuimos escapados de la muerte por que nos iban a matar». Cuando le plantean a la persona en condición de desplazamiento la posibilidad de retornar a su sito de origen, al parecer ellos lo interpretan como una forma de re-desplazamiento: desplazar al desplazado de la zona receptora. En uno de los comentarios se manifiesta, por ejemplo, que «[1] as entidades no quieren que los desplazados se queden sino que retornen a su lugar de origen»; como si no se entendiese que los lugares de origen aún representan alto riesgo para las familiasen condición de desplazamiento, quienes consideran que la muerte -representada en los actores armados- los espera. Para algunos la posibilidad de trabajar en el sector rural genera temor debido a las circunstancias de violencia e inseguridad. Así, el retorno a su lugar de origen y la posibilidad de re-encontrarse con su tejido social se presenta ante ellos como una utopía : «[y]o retornaría cuando se arregle el país». 


\section{Francisco Javier Portilla Guerrero}

El des-hacer de la violencia: socialización de una experiencia de atención psicosocial a niños y niñas víctimas de la violencia por conflicto armado en Colombia desde el marco interpretativo de las artes plásticas, artículo producto de la investigación

Muchos de ellos comparten la vivienda, y muchas veces vive más de una familia por habitación. Generan ingresos mínimos de actividades de rebusque y las madres cabeza de familia, por ejemplo, trabajan en reciclaje o venden mercancía por temporada, lavan ropa o se dedican al servicio doméstico. Los hombres trabajan en construcción como albañiles, en celaduría o en carga. Afirman ellos que las instituciones brindan capacitaciones para desempeño laboral pero que estas resultan improductivas frente a la escasa oferta laboral y la masiva competencia. «Estamos llenos de diplomas de capacitación pero no podemos hacerlos efectivos por la falta de oportunidades», afirma un líder de asociación que nove en las instituciones más que una oportunidad frustrada.

Las situaciones y condiciones de desplazamiento fracturan la unidad familiar; padres, hijos y parejas se ven obligados a separarse:

Tres enmascarados nos obligaron a desocupar... a mi esposo se lo llevaron los paras a las once de la noche, lo golpearon el todavía sufre de la cabeza a causa de los golpes... Allá teníamos cuyes, marranos, gallinas, mi mama que se quedo allá dice que todo se lo comieron que ya no hay nada.

Entre los motivos más constantes de desplazamiento están por la posibilidad de que la guerrilla reclute a sus hijos o intenten abusar sexualmente de sus hijas:

Trataron de violarnos, nos dieron cinco minutos y salimos yo no mas cogí los papeles de ellos (refiriéndose a los documentos de identidad de sus hijos)... mi papá murió mas primero, mi tío desapareció... llegaron ellos (grupo armado no definido) dijeron que les maten gallinas y luego quisieron aprovecharse de nosotras... yo no quiero volver porque la experiencia me puede volver a pasar.

Otro de los motivos son amenazas directas y asesinatos a miembros de la familia, como lo expresa una víctima: «[m]e mataron un sobrino, me amenazaron los hijos, me los iban a llevar...»

El dibujo y la pintura como herramienta de atención psicosocial en la interpretación hermenéutica desde la exploración plástica en los niños víctimas de la violencia en los Municipios de La Cruz, Mosquera, Cumbitara y Leiva en el departamento de Nariño

La intención aquí es la de hacer un tejido de lectura hermenéutica con la variante del rol del arte asumido dentro de los cánones de la metáfora. Se plantea como interrogante su utilidad en un sistema que existe desde la visión alegórica y que margina toda intención metafórica por temor a una anarquía tal vez no valorada desde sus posibilidades dialécticas. 
Nuestro pensar supone siempre la comprensión de otras personas; somos en él nos somos es el otro quien, en una interesante proporción, define la interpretación del auto- concepto fundamentado en la comprensión. Es decir, sólo en la comparación de mí mismo con otros adquiero yo la experiencia de lo individual. Y en los dibujos y pinturas de los niños no solamente se proyectan las individualidades del autor sino que confluyen todas las individualidades de los posibles lectores provistos de mundos que no precisan de un intérprete para que les guíe por la senda de lo que deberían sentir -de acuerdo a las intenciones del autor o las tendencias de la crítica-. Vale la pena aclarar que desde el Arte, al contrario de la Psicología, puede ser mucho más valida la introspección que la proyección puesto que una obra (dibujo, pintura o cualquier otra manifestación plástica o visual), al estar en situación comunicativa, está sujeta a un sinfín de posibilidades interpretativas, todas ellas iguales en su validez más no en sus signos y significados. Esto genera múltiples dialécticas derivadas de las lecturas, que por muy descabelladas que parezcan en apariencia, también son el resultado de un ser que siente, observa, comprende y por lo tanto interpreta a los demás y a sí mismo a partir de esa causa que lo referencia: la obra de arte. Así, en la percepción de la violencia desde los grafismos de un niño, el otro puede también o no ser un símil, siendo aquello que, tocado por la interpretación, deja de ser inanimado y pasa a ser referente de auto-comprensión en el eterno racionamiento del quehacer humano en el contexto cotidiano..

El arte es varias cosas, pero en primer término es un intento desesperado de comunicación, mediante un lenguaje, sea la palabra, la pintura, o la música, que va mucho más allá del lenguaje de todos los días (Sábato, 1991). El artista, el que terminará siendo artista, es un niño introvertido que se siente melancólicamente aislado e incomprendido, y que tímidamente empieza haciendo garabatos absurdos que serán más tarde el fundamento de su obra.

El arte entendido como metáfora busca entonces desde sus signos develar al niño, ese ser ausente que hace presencia en aquellas causas no cosas de las cuales se vale en el devenir de sus cotidianidades, en este caso en particular las manifestaciones violentas de la guerra, en espera de ser interpretado y comprendido. La función de los dibujos es la de participar en la intención de reflexión pues busca que el niño acceda a un mundo desde las irrealidades alegóricas para ser en sí mismo la metáfora que incline lo humano sintiente desde los signos del pensante. Todo lo anterior en una auto-búsqueda que, como reflejo de lo externo, permite al niño verse a sí mismo absuelto de los códigos de guerra y violencias de las cuales él no es responsable.

Los dibujos, cuando salen de las manos del niño víctima de violencia, buscan por sí mismos su propio sentido de alteridad, que por sus intenciones y circunstancias vive de la confrontación de su decir con el sentir frente al 


\section{Francisco Javier Portilla Guerrero}

El des-hacer de la violencia: socialización de una experiencia de atención psicosocial a niños y niñas víctimas de la violencia por conflicto armado en Colombia desde el marco interpretativo de las artes plásticas, artículo producto de la investigación

hecho violento, llevando implícito el símbolo y su símbolo en una catarsis chamánica de auto- comunicación.

Entre las necesidades de la población infantil víctima de la violencia y desplazamiento por conflicto armado en Colombia se han encontrado lo siguiente: temor a la gente extraña o ajena al municipio, cambios comportamentales en los niños, un mal manejo de los conceptos de lo bueno y lo malo en relación con los actores armados, interiorización de términos bélicos, resentimiento y manifestaciones de venganza sobre uno de los actores armados, limitaciones en su desempeño cotidiano y expresiones en razón del miedo, deserción escolar, temor a acercarse a la estación de policía, el policía como ente de riesgo, temor a la llegada del avión fantasma, manejo de gestos agresivos, expresiones gestuales violentas, actos repetitivos de violencia, juegos de representaciones bélicas, sentimientos de desconfianza e inseguridad, entre otros.

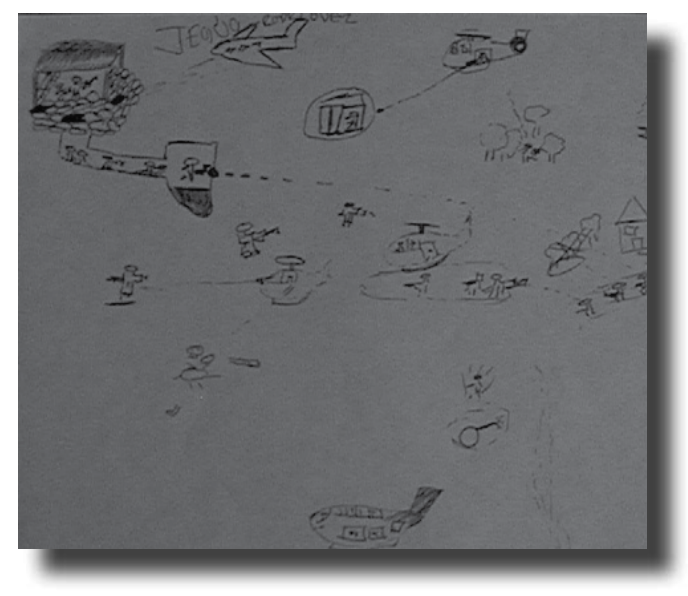

Figura 1. Dibujo de Pablo (12 años) ilustrando el enfrentamiento entre ejército y guerrilla acontecido en el municipio de Cumbitara, una semana después.

En general, se ha observado que la violencia impacta en forma discriminada a los niños: de acuerdo al tipo de experiencia a la que ha sido expuesto, a la estructura psicológica que ha alcanzado y la edad cronológica en la que se encuentra. Asumen el acto violento en relación con el temor del adulto y en doble vía negativa. Muchos de ellos lo consideran como parte inherente a la cotidianidad y en otros les mutila el derecho la fantasía infantil, negándoles la posibilidad de ser gestores de su imaginario y reemplazarlo por lenguajes de connotación bélica donde el indio y el vaquero fueron remplazados por el policía, el «paraco» (paramilitar) y el guerrillero. Más aun, los niños se refugian en el miedo y se niegan a vivir su cotidianidad. 
El impacto de la violencia en el niño puede observarse a partir de sus dibujos, donde sin importar el municipio se manifiestan como íconos representativos de la violencia los cilindros de gas, el avión fantasma, las balas y los muertos, y se reconocen como ajenos al conflicto pero a su vez como víctimas del mismo.

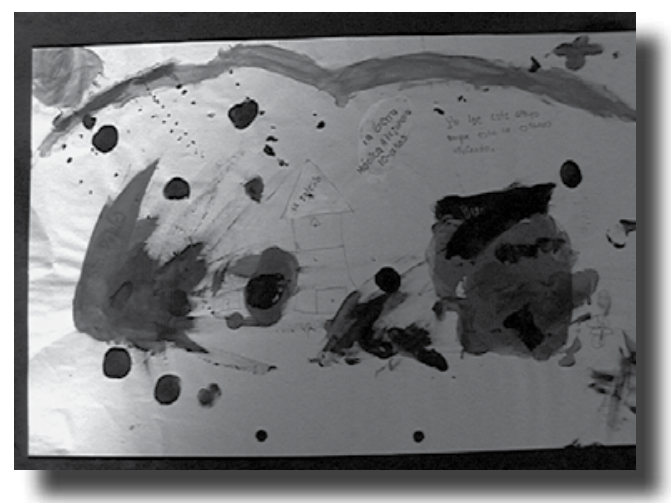

Figura 2. Mixta de Mónica (10 años.) Representación de la toma guerrillera en el municipio de La Cruz Nariño.

El miedo, los simulacros, los lugares aparentemente seguros y aquellos de inminente riesgo hacen parte de la cotidianidad infantil. Así mismo, términos como los de «guerros» o «paracos» son constantes en sus lenguajes. Sin embargo, siguen anhelando esos espacios de juego donde su inocencia infantil hace de la lúdica uno de los medios para la elaboración de su catarsis.

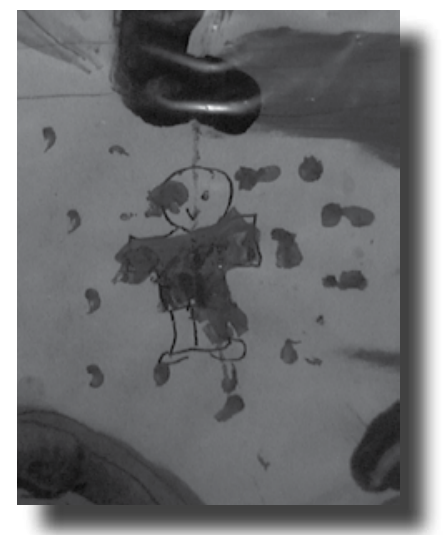

Figura 3. Dibujo antropomorfo de Carlos. ( 5 años) representación de un muerto víctima de la toma guerrillera en el municipio de Cumbitara

«En el ataque guerrillero me dio miedo, estube en mi casa en un cuarto de abajo y nos escondimos hasta que paso el ataque después que se habian rendido los policias salimos al patio y habia un silindro y nosotros salimos de la casa...» 


\section{Francisco Javier Portilla Guerrero}

El des-hacer de la violencia: socialización de una experiencia de atención psicosocial a niños y niñas víctimas de la violencia por conflicto armado en Colombia desde el marco interpretativo de las artes plásticas, artículo producto de la investigación

El dibujo de sí mismo en muchos de los casos manifiesta características derivadas de la baja autoestima, representada y expresada a través de la ausencia de partes corporales, tamaño en relación con el soporte, expresiones faciales tristes, posición del dibujo en el papel etc. Por otro lado, el dibujo de la familia devela cómo se siente el niño en relación con sus parientes. Algunos de los dibujos manifiestan separación afectiva, el rol afectivo de los padres para con el niño, la ausencia de uno más miembros de la familia e incluso se muestran familias muy numerosas donde el niño comparte el afecto con varios hermanos de edades similares.

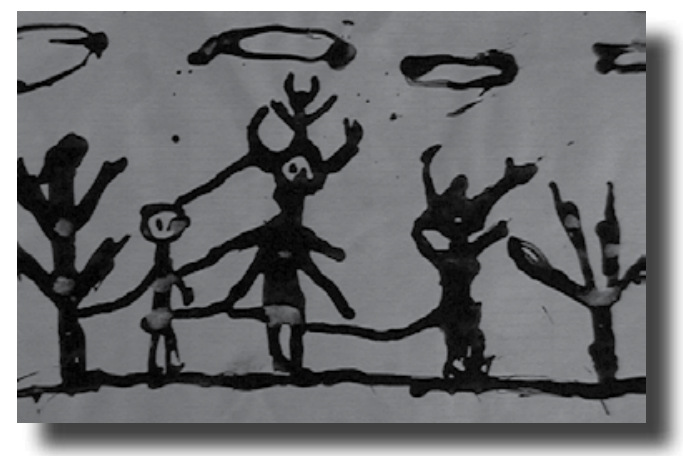

Figura 4. Dibujo de Rene (9 años.) representación de la familia. Cumbitara

«Luego que siguieron echando tiros los guerrilleros le dijeron a los policias que se entreguen y que les daban 20 minutos para que entreguen las armas luego fuimos para el pueblo y miramos ami abuelito erido y a muchos señores del pueblo».

Así pues, el dibujo del acto violento permite hacer una lectura de cómo el niño lo interpreta, a quién considera responsable de tal acto, y cómo se define él y a los suyos dentro de las víctimas.

\section{Desde lo psicosocial...}

Dentro del análisis de lo manifestado en los trabajos pictóricos realizados por la población infantil en el marco del proceso de atención psicosocial fueron evidentes sentimientos de temor y desconfianza a raíz de hecho violento. También hubo, no obstante, un alto índice de receptividad y emotividad, capacidad de restablecimiento, así como enormes habilidades creativas, imaginativas y solidarias, que prevén opciones positivas por parte de los niños en el restablecimiento de su tejido social.

Con niños entre los dos y cuatro años de edad se desarrollaron actividades cuyo énfasis fue el juego, la recreación y la exploración plástica con el fin de minimizar la experiencia violenta y suplirla por una experiencia recreativa. 
Con niños de cinco y nueve años, se utilizaron talleres gráficos como elementos de expresión emocional donde se buscó proyectar el impacto del acto violento para generar catarsis, juegos tradicionales que intentaron remplazar los juegos bélicos y de imitación del conflicto armado y cuentos que buscaron dejar enseñanzas para sensibilizar a los niños sobre su proyecto de vida.

Con niños de diez y catorce años los talleres de expresión gráfica y textual así como los socio dramas, buscaron expresar emociones y, por otro lado, los cuentos y narraciones se encaminaron a abrir espacios de reflexión, diálogo y trabajo en equipo. Los talleres con niños de quince y diecisiete años los llevaban a valorarse como multiplicadores, apoyándose en actividades de expresión pictórica textual y socio dramas, así como charlas de opinión frente al conflicto y sus posibilidades.

Por otra parte, con docentes se realizaron foros sobre los imaginarios del niño en relación a la violencia y cómo ellos pueden ser partícipes de dichos imaginarios para una mayor comprensión de sus educandos. Cada uno de los talleres se adecuaa la edad de la población, así como a sus características culturales y sus niveles socioeconómicos. Esto con el fin de generar un mayor sentido de empatía y calidez.

El pasado es tenaz, por la sencilla razón de que guarda muchas claves del presente (Berinstain, 2000). Cuando un pueblo se pregunta quién es, se ve forzado a plantearse cómo pudo suceder eso y por qué se dejó someter. Eso supone confrontarse con la necesidad de asimilar experiencias brutales o de lo contrario, refugiarse en la negación y la falsa ignorancia.

En relación al diagnóstico encontrado en los diferentes municipios intervenidos, hay que decir que dentro del término «menor de edad» se incluyen niños y jóvenes con edades entre los dos y diecisiete años de edad, víctimas de violencia o de desplazamiento. Por lo tanto, para cada rango de edades se deben establecer objetivos y estrategias psicosociales diferentes durante las actividades. De igual forma, dependiendo del tipo de evento y de las particularidades culturales de cada región se hicieron distintas actividades que iban desde la lúdica hasta la expresión textual o gráfica, incluyendo socio dramas o mini foros.

Durante la etapa de intervención, y teniendo en cuenta que los derechos del niño prevalecen por encima de los demás, se abordó desde el perfil profesional a la población infantil con el fin de reforzar conductas y actitudes positivas que sustituyan experiencias negativas. Se planteó organizar actividades en las que los niños y las niñas tuvieran oportunidad de expresar lo ocurrido, "de mantener un sentido de seguridad y de estar activos permitiéndoles sentir, de esa manera, que efectivamente son tomados en cuenta. "Para ello se tuvo en cuenta cómo se ven a sí mismos y la forma en que se ven en relación con su 


\section{Francisco Javier Portilla Guerrero}

El des-hacer de la violencia: socialización de una experiencia de atención psicosocial a niños y niñas víctimas

de la violencia por conflicto armado en Colombia desde el marco interpretativo de las artes plásticas, artículo producto de la investigación

familia. Igualmente se desempeñaron en actividades que necesitan del trabajo en equipo para así fortalecer su tejido social.

Muchas de las actividades realizadas en el área de artes plásticas con niños y adultos encontraron un afán comunicativo, un deseo de compartir con otros lo vivido, de establecer un diálogo que permita conciliar una respuesta positiva y en contra de la barbarie.Muchas de las actividades son sencillas, pero es en esa simplicidad donde convergen emociones y sentires yrelaciones de empatía con el otro donde se le reconoce como igual en su diferencia. Todo en ese momento corto de compartir un frasco de pintura o un lápiz o tal vez en ese infantil deseo de que los juegos duren para siempre.

Es en ese pequeño espacio de taller, de lúdica, de cuento, donde los participantes pueden darse cuenta que para develar una posición no hace falta eliminar al adversario, sino que basta solo con tolerarlo, convencerlo o permitir que convenza; todo en aras de convivir en comunidad y disfrutar de aquello que los intolerantes les están quitando.

Dentro de los logros se identifican actitudes emocionales positivas, buen desarrollo psicomotor, confianza y aceptación; gran destreza en el manejo del dibujo en relación con sus edades, así como creatividad plástica; altos niveles de tolerancia y solidaridad frente al trabajo en equipo, expresiones y comentarios de adaptación y reconstructivos a partir del evento violento; expectativas frente a las posibilidades artísticas en el aprovechamiento del tiempo libre. No es mucho, pero es algo que desencadena abrazos, risas, trabajo en equipo, constancia y creatividad, simples ganas de ser haciendo, demostrando entre susurros que hay otro camino diferente al de las armas y los muertos.

\section{Referencias bibliográficas}

Beristain, C. M. 2000. "Justicia y Reconciliación. El papel de la verdad y la justicia en la reconstrucción de sociedades fracturadas por la violencia». Cuadernos de Trabajo de Hegoa. 27: 1-40.

Debray, R. 1993. Vida y muerte de la imagen. Historia de la mirada en Occidente. Barcelona: Paidós.

Deleuze, G. 1996. Crítica y clínica. Barcelona: Anagrama.

Derrida, J. 1990. «Interview with Peter Brunette and David Wills», en P. Brunette y D. Wills (Comps.), Decostruction and Visual Arts. 9-32. Cambridge: Cambridge University Press. 


\section{Revista de}

investigaciones UNAD

Volumen 10. Número 2. Diciembre 2011

Levinas, E. 2002. Totalidad e infinito. Ensayo sobre la exterioridad. Salamanca: Ediciones Sígueme.

Sábato, E. 1989. Entre la letra y la sangre. Conversaciones con Carlos Catania. Barcelona: Seix Barral.

Sartre, Jean-Paul. 1983. El existencialismo es un humanismo. Barcelona: Ultramar. 